\title{
A Study on Copolymer Systems of Styrene with Diethanolamine Side Group and Methyl Methacrylate
}

\author{
Aslisah Acikses $\left(\mathbb{D},{ }^{1}\right.$ Gokce Taskan, ${ }^{1}$ and Gamze Barim ${ }^{2}{ }^{2}$ \\ ${ }^{1}$ Department of Chemistry, Faculty of Science, Firat University, 23119 Elaziğ, Turkey \\ ${ }^{2}$ Department of Chemistry, Faculty of Science and Arts, Adiyaman University, 02040 Adiyaman, Turkey \\ Correspondence should be addressed to Aslisah Acikses; bacikses@firat.edu.tr
}

Received 16 November 2017; Revised 24 January 2018; Accepted 29 January 2018; Published 10 April 2018

Academic Editor: Mohammad A. Al-Ghouti

Copyright (C) 2018 Aslisah Acikses et al. This is an open access article distributed under the Creative Commons Attribution License, which permits unrestricted use, distribution, and reproduction in any medium, provided the original work is properly cited.

\begin{abstract}
4-Diethanolaminomethyl styrene (DEAMSt) monomer was prepared by the modification of 4-chloromethyl styrene with diethanolamine. The copolymers in different combinations $(0.11,0.19$, and 0.30 by mole) of DEAMSt and methyl methacrylate (MMA) were prepared by free radical polymerization method at $60^{\circ} \mathrm{C}$ in the presence of 1,4 -dioxane and AIBN as initiator. The structures of DEAMSt and DEAMSt-MMA copolymer were characterized by FT-IR and ${ }^{1} \mathrm{H}$-NMR. The glass transition temperature $\left(T_{q}\right)$ of the copolymers was measured by DSC. Thermal decomposition behavior of the copolymers was investigated by TGA. The average molecular weights of the copolymers were determined by GPC. The dye uptaking properties of the copolymers were investigated using bromocresol green. Then, the dielectric constant, dielectric loss factor, and conductivity of copolymers were investigated as a function of temperature and frequency. The activation energies $\left(E_{a}\right)$ of the copolymers were determined by impedance analyzer.
\end{abstract}

\section{Introduction}

The 4-chloromethyl styrene is known as one of the important functional monomers. Since 4-chloromethyl styrene carries an active halogen against the nucleophilic reactant, much work has been done on the modification on chloromethyl group of its homo- and copolymers. In particular, because the amine-modified 4-chloromethyl styrene polymers have the ability to retain moisture, $\mathrm{CO}_{2}$, acidic substances, and metal ions, so much work has been done on this subject $[1,2]$. Various graft copolymers have been synthesized by the modification of 4-chloromethyl styrene. The free radical polymerization (SRP) and atom transfer radical polymerization (ATRP) methods were used in the syntheses. The ATRP procedure of 4-chloromethyl styrene makes the addition of a new monomer to a polymer possible [3].

The 4-chloromethyl styrene, which has functional structure as both a monomer and an initiator, yields partially branched and hyperbranched structures $[4,5]$. Poly(St-co-4chloromethyl styrene) is convenient to use as a macroinitiator for grafting the monomers such as ethyl methacrylate [6], styrene, and p-acetoxy styrene on the polystyrene chain
[7]. A two-armed macroinitiator was prepared by means of poly(St-co-4-chloromethyl styrene), and it had been copolymerized with isobornyl acrylate via ATRP [3]. The modifications of poly(4-chloromethyl styrene) were carried out using PS-imidazole, PS-diethanolamine, PS-piperazine, and PS-dimethylamine [8]. The polystyrene-based terpyridine polymer was prepared from 4-chloromethyl styrene [9].

This manuscript focuses mainly on thermal characterization, electrical properties, and adsorption kinetics of a series copolymer systems containing DEAMSt and MMA. The changes in the physical and chemical behaviors due to increasing in the $-\mathrm{OH}$ and amine groups, which are found in the DEAMSt moieties in the copolymer systems, were especially investigated and how the electrical properties of the copolymers change depending on the increase in DEAMSt was investigated. In this context, series copolymer systems containing methyl methacrylate (MMA) and DEAMSt synthesized by the modification of 4-chloromethyl styrene with diethanolamine were prepared by free radical polymerization. The structural characterization of the products was carried out by FT-IR and ${ }^{1} \mathrm{H}-\mathrm{NMR}$, and the other properties were investigated by TGA, DSC, GPC, and impedance 


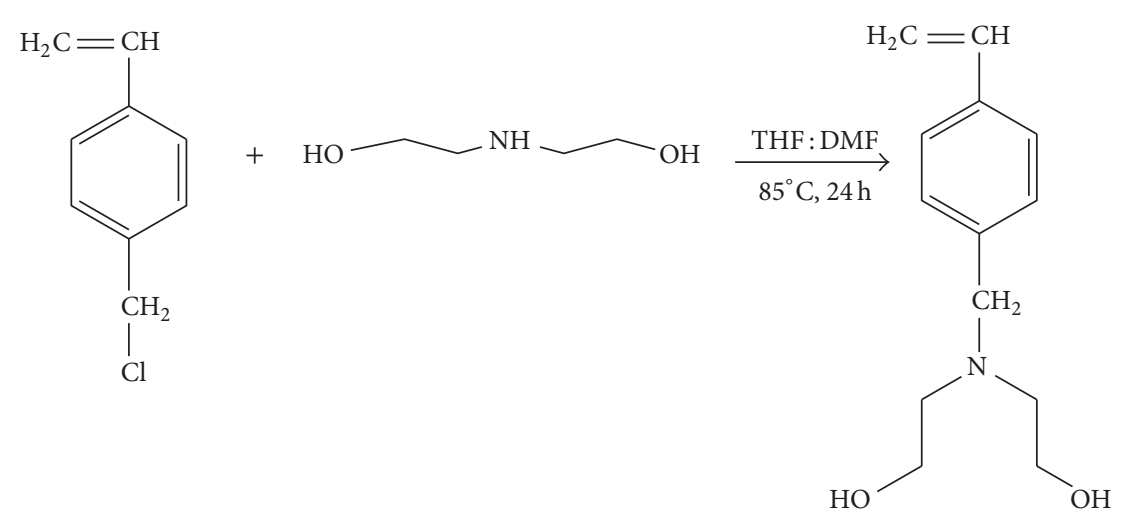

FIGURE 1: Synthesis reaction of DEAMSt monomer.

analyzer. The adsorption kinetics of the copolymers were studied by UV.

\section{Materials and Methods}

2.1. Materials. 4-Chloromethyl styrene (CMS) and methyl methacrylate (MMA) (Aldrich) were distilled under vacuum before use. Diethanolamine (DEAM), tetrahydrofuran (THF), N,N-dimethylformamide (DMF), 2,2'-azobisisobutyronitrile (AIBN), ethyl alcohol (Fluka), n-hexane, 1,4dioxane, dichloromethane, sodium bicarbonate $\left(\mathrm{NaHCO}_{3}\right)$, sodium hydroxide $(\mathrm{NaOH})$, and bromocresol green (BCG) were used as received without any further purification.

2.2. Characterization Techniques. The structure of the monomer and copolymers was characterized by a Perkin-Elmer Spectrum One FT-IR and a $400 \mathrm{MHz}$ Avance III Bruker ${ }^{1} \mathrm{H}$ NMR Spectrometer, using D-chloroform as a solvent. The calorimetric measurements were performed using Shimadzu DSC-50 thermal analyzer with the heating rate of $20^{\circ} \mathrm{C} / \mathrm{min}$ under $\mathrm{N}_{2}$ flow. The thermal behaviors were investigated using a Shimadzu TGA-50 thermobalance with a heating rate of $10^{\circ} \mathrm{C} / \mathrm{min}$ under $\mathrm{N}_{2}$ flow. The average molecular weights of the copolymers were measured using an Agilent 1100 series Gel Permeation Chromatography (GPC). The measurements were carried out at $25^{\circ} \mathrm{C}$ using RI detector at $1 \mathrm{~mL} / \mathrm{min}$ solvent flow rate and used the polystyrene as standard and THF as a solvent. The dye uptake properties of the obtained copolymers were investigated using a T80+ UV/VIS spectrophotometer. Bromocresol green (BCG) was used as an adsorbent. The dye uptake properties were studied at room temperature $(\mathrm{pH}=3.8-5.5$ and $\lambda \max =350 \mathrm{~nm})$. The electrical measurements were carried out at $298 \mathrm{~K}$ and $423 \mathrm{~K}$ with a QuadTech 7600 precision LRC Meter impedance analyzer over the frequency range between $100 \mathrm{~Hz}$ and $2 \mathrm{kHz}$.

2.3. Modification of 4-Chloromethyl Styrene (CMS) with Diethanolamine (DEAM). The modification of 4-chloromethyl styrene with diethanolamine was carried out according to the method adapted from the literature $[7,10]$. For this purpose, $10 \mathrm{~g}(0.065 \mathrm{~mol})$ of 4 -chloromethyl styrene was placed into a $100 \mathrm{~mL}$ three-necked reaction flask and dissolved in $10 \mathrm{~mL}$

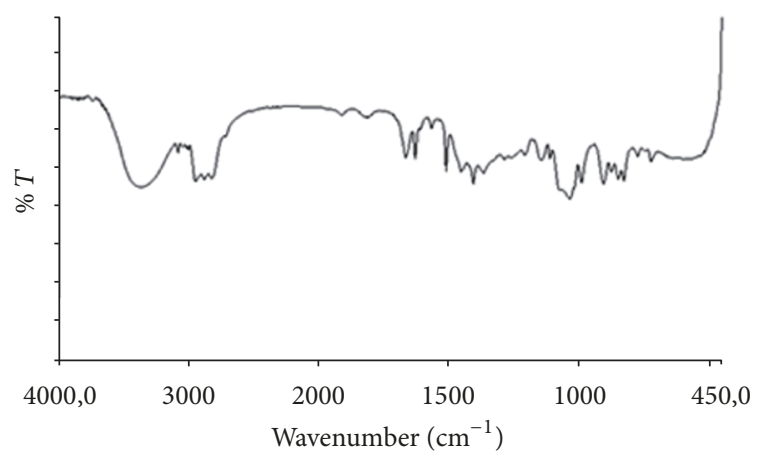

FIgURE 2: The FT-IR spectrum of DEAMSt monomer.

THF and $20 \mathrm{~mL}$ DMF solvent mixture. Then, $10 \mathrm{~g}(0.098 \mathrm{~mol})$ $\mathrm{NaHCO}_{3}$ and $13.6 \mathrm{~g}(0.120 \mathrm{~mol})$ diethanolamine were added to the solution. The hydroquinone (ppm level) was added to the mixture in order to prevent polymerization. The solution was stirred and heated for $24 \mathrm{~h}$ at $85^{\circ} \mathrm{C}$ under reflux. After the completion of the reaction, the mixture was washed with an aqueous solution of $\mathrm{NaOH}$ ( $5 \%$ by weight) in order to remove hydroquinone. The reaction mixture was cooled to room temperature and filtered. The filtrate was dried over anhydrous $\mathrm{MgSO}_{4}$ and the solvent was removed by rotary evaporator (Figure 1). The boiling point of DEAMSt could not be observed due to polymerization of the monomer at 1 atmosphere pressure. The yield of DEAMSt monomer was estimated as $49 \%$ (by weight). The structure of the modified monomer was characterized by FT-IR and ${ }^{1} \mathrm{H}-\mathrm{NMR}$ (Figures 2 and 3$)$.

2.4. The Copolymerization of Modified DEAMSt with Methyl Methacrylate (MMA). The synthesis of copolymers was carried out by free radical polymerization method. DEAMSt and MMA monomers were placed into three different polymerization tubes. For this purpose, three different reaction tubes were prepared (first tube: $0.442 \mathrm{~g}(0.002 \mathrm{~mol})$ DEAMSt, $1.800 \mathrm{~g}$ ( $0.018 \mathrm{~mol}) \mathrm{MMA}$, and $0.022 \mathrm{~g}$ AIBN; second tube: $0.884 \mathrm{~g}$ (0.004 mol) DEAMSt, $1.600 \mathrm{~g}(0.016 \mathrm{~mol}) \mathrm{MMA}$, and $0.003 \mathrm{~g}$ AIBN; third tube: $0.326 \mathrm{~g}(0.006 \mathrm{~mol})$ DEAMSt, 


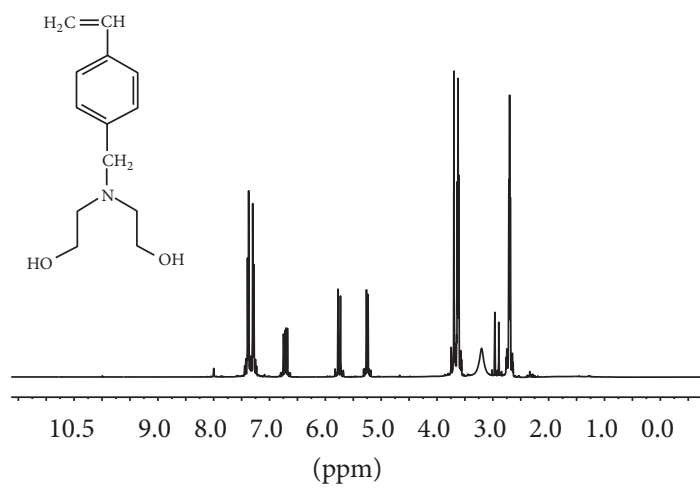

Figure 3: The ${ }^{1} \mathrm{H}$-NMR spectrum of DEAMSt monomer.

$1.400 \mathrm{~g}$ (0.014 mol) MMA, and 0.014 g AIBN) in which 1,4dioxane was used as solvent and AIBN was used as initiator. Each mixture was passed from argon gas flows for $10 \mathrm{~min}$. Every tube of polymerization was closed, and the mixture of monomers was polymerized within a thermostated oil bath at $60^{\circ} \mathrm{C}$ for $24 \mathrm{~h}$. The prepared copolymers were diluted with dichloromethane solvent, and they were precipitated within $\mathrm{n}$-hexane. The synthesized copolymers were dried at $40^{\circ} \mathrm{C}$ under vacuum (Figure 4). The structure of P(DEAMSt-coMMA) was characterized by FT-IR and ${ }^{1} \mathrm{H}-\mathrm{NMR}$.

\section{Results and Discussion}

3.1. The Characterization of Modified DEAMSt Monomer and $P(D E A M S t-c o-M M A)$. The 4-diethanolaminomethyl styrene was prepared from the modification of 4-chloromethyl styrene with diethanolamine. The copolymers of the modified styrene monomer and methyl methacrylate in various combinations (11, 19, and $30 \%$ by mole) were prepared by free radical polymerization method. In the FT-IR spectrum of the modified DEAMSt monomer (Figure 2), the $-\mathrm{OH}$ stretching vibration at $3400 \mathrm{~cm}^{-1}$, the aromatic C-H stretchings at $3082-3050 \mathrm{~cm}^{-1}$, the aliphatic $\mathrm{C}-\mathrm{H}$ stretchings at $2920-2850 \mathrm{~cm}^{-1}$, the $\mathrm{C}=\mathrm{C}$ double bond stretching on aromatic ring at $1600 \mathrm{~cm}^{-1}$, the aromatic $\mathrm{C}-\mathrm{H}$ bending at $1490 \mathrm{~cm}^{-1}$, the aliphatic C-H bending at $1450-1370 \mathrm{~cm}^{-1}$, the $-\mathrm{C}-\mathrm{N}$ vibration bending at $1386,1100-1250 \mathrm{~cm}^{-1}$, and the $\mathrm{C}-\mathrm{H}$ plane bending vibration at $690-830 \mathrm{~cm}^{-1}$ are the characteristic peaks for the structure. The structure of 4-chloromethyl styrene performed in the previous studies in our laboratory $[3,11]$ was characterized by FT-IR, and the $-\mathrm{CH}_{2}-\mathrm{Cl}$ and $-\mathrm{C}-\mathrm{H}$ bending vibrations at $1265 \mathrm{~cm}^{-1}$ and the $\mathrm{C}-\mathrm{Cl}$ stretching at $673 \mathrm{~cm}^{-1}$ were observed. Additionally, the ${ }^{1} \mathrm{H}$-NMR spectrum showed the signals at $4.5 \mathrm{ppm}$ for $-\mathrm{CH}_{2}$ $\mathrm{Cl}$ protons. The FT-IR spectrum of the DEAMSt monomer showed a broad - $\mathrm{OH}$ band at $3400 \mathrm{~cm}^{-1}$, the disappearance of the $-\mathrm{CH}_{2}-\mathrm{Cl}$ bending vibration at $1265 \mathrm{~cm}^{-1}$, and the disappearance of the $\mathrm{C}-\mathrm{Cl}$ stretching at $673 \mathrm{~cm}^{-1}$, and a new broad peak appeared at $1070 \mathrm{~cm}^{-1}$ which is characteristic for $\mathrm{C}-\mathrm{O}$ bonding and indicates that the structure was formed successfully [12]. The ${ }^{1} \mathrm{H}-\mathrm{NMR}$ spectrum of the DEAMSt monomer (Figure 3) showed the aromatic ring protons at $7.38-7.30 \mathrm{ppm}$, phenyl- $\mathrm{CH}_{2}-\mathrm{N}$ and $-\mathrm{CH}_{2}-\mathrm{O}$ protons at $3.69 \mathrm{ppm},-\mathrm{CH}_{2}$ protons next to nitrogen $\left(\mathrm{N}^{-} \mathrm{CH}_{2}\right)$ at $2.89 \mathrm{ppm}$, cis-trans $-\mathrm{CH}_{2}$ protons at $5.23-5.73 \mathrm{ppm}$, and $\mathrm{CH}_{2}$ and $-\mathrm{CH}$ protons at $2.2-1.8 \mathrm{ppm}$ on the main chain. The signals at 8.00 and $2.89-2.96 \mathrm{ppm}$ belong to the solvent (DMF), which can not be removed from the medium.

The FT-IR spectra of the copolymers in different combinations [P(DEAMSt0.11-co-MMA), P(DEAMSt0.19co-MMA), and P(DEAMSt0.30-co-MMA)] are showed in Figure 5. The significant bands in the spectra are - $\mathrm{OH}$ stretching vibration peak at $3456 \mathrm{~cm}^{-1}$, the aromatic $-\mathrm{C}-\mathrm{H}$ stretching peak at $3000-3050 \mathrm{~cm}^{-1}$, the aliphatic $-\mathrm{C}-\mathrm{H}$ stretching peak at $2950 \mathrm{~cm}^{-1}$, the $-\mathrm{OC}=\mathrm{O}$ carbonyl peak in the MMA unit at $1729 \mathrm{~cm}^{-1}$, the aromatic $\mathrm{C}=\mathrm{C}$ bond stretching at $1600 \mathrm{~cm}^{-1}$, the aromatic $\mathrm{C}-\mathrm{H}$ bending at $1490-1510 \mathrm{~cm}^{-1}$, and the aliphatic $\mathrm{C}-\mathrm{H}$ bending at $1447 \mathrm{~cm}^{-1}$, and at 1148 and $1250 \mathrm{~cm}^{-1}$ a wide peak of $\mathrm{C}-\mathrm{N}$ vibrations was observed.

The ${ }^{1} \mathrm{H}-\mathrm{NMR}$ spectra of the prepared copolymers in different combinations are given in Figure 6. In the ${ }^{1} \mathrm{H}-\mathrm{NMR}$ spectrum, the aromatic ring protons at $6.9-7.2 \mathrm{ppm}$, the $\mathrm{OCH}_{3}$ protons in the MMA units, the phenyl- $\mathrm{CH}_{2}-\mathrm{N}$ and $\mathrm{CH}_{2}-\mathrm{O}$ protons at $3.6 \mathrm{ppm},-\mathrm{N}-\mathrm{CH}_{2}$ proton at $2.8 \mathrm{ppm}$, the $-\mathrm{CH}_{2}$ and $-\mathrm{CH}$ protons in the polymeric chain at $1.1-2.1 \mathrm{ppm}$ are important signals, and the $-\mathrm{CH}_{2}-\mathrm{Cl}$ signal at $4.5 \mathrm{ppm}$ disappeared after the modification of 4-chloromethyl styrene with diethanolamine. The new signals at $3.6 \mathrm{ppm}$ and at $2.8 \mathrm{ppm}$ corresponding to the bonded phenyl $-\mathrm{CH}_{2}-\mathrm{N}$ and $-\mathrm{CH}_{2}-\mathrm{O}$ protons and next to nitrogen $-\mathrm{CH}_{2}$ proton are characterizing the structure of $\mathrm{P}$ (DEAMSt-co-MMA).

The combination of the copolymers was estimated from the ${ }^{1} \mathrm{H}$-NMR spectra. For this purpose, the considerable integral heights of the aromatic ring protons $(6.8-7.5 \mathrm{ppm})$ and integral heights of the aliphatic protons $(0.6-2.2 \mathrm{ppm})$ on the main chain of copolymer were utilized to calculate the percentage combinations of DEAMSt and MMA. The composition of the copolymers was calculated by means of the following equations.

$$
\begin{aligned}
\frac{\text { Aromatic protons integral heights }}{\text { Aliphatic protons integral heights }}= & \frac{4 m_{1}}{3 m_{1}+5 m_{2}}, \\
& \left(m_{1}+m_{2}=1\right) .
\end{aligned}
$$

Here, $m_{1}$ is the mole fraction of the (DEAMSt); $m_{2}$ is the mole fraction of the MMA.

The composition of the DEAMSt-MMA copolymer systems was estimated as DEAMSt0.11, MMA0.89; DEAMSt0.19, MMA0.81; DEAMSt0.30, MMA0.70. The feed ratios of DEAMSt in copolymerization are $0.10,0.20$, and 0.30 by mole. On the other hand, units of DEAMSt after copolymerization are $0.11,0.19$, and 0.30 by mole. This means that reactivity of monomers is almost the same as each other.

The average molecular weights and polydispersities of the copolymers were estimated by GPC technique and the results were summarized in Table 1. Polydispersities of copolymers prepared by free radical polymerization method showed the formation of chains with narrow molecular structure. 


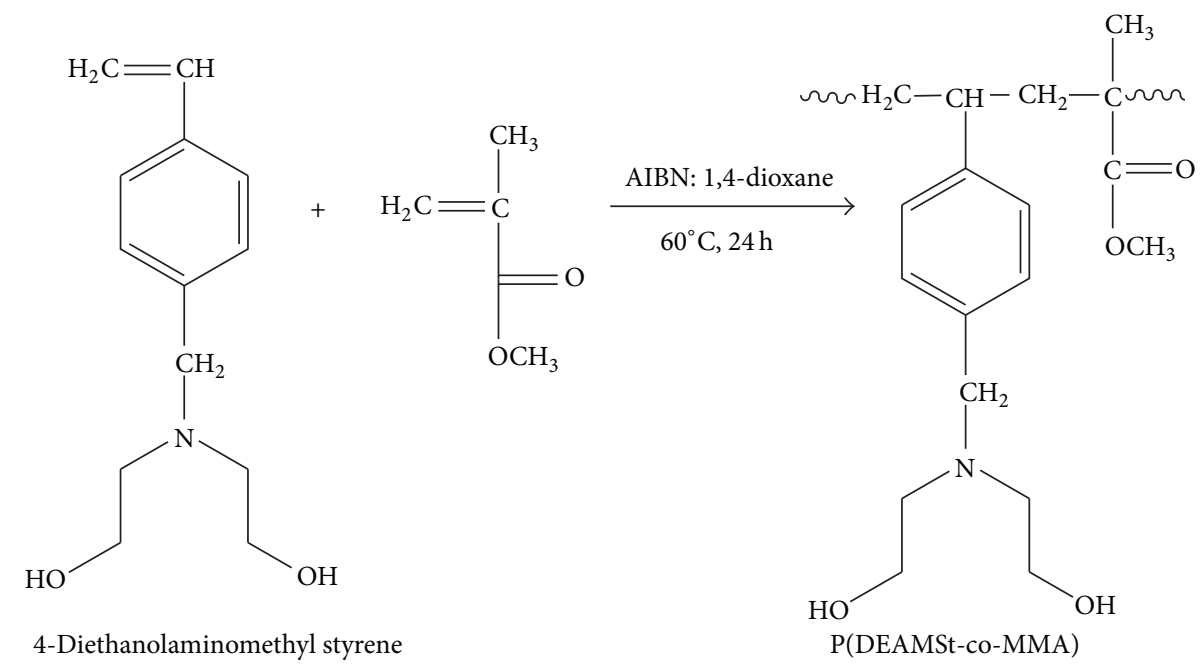

FIGURE 4: Synthesis reaction of P(DEAMSt-co-MMA).

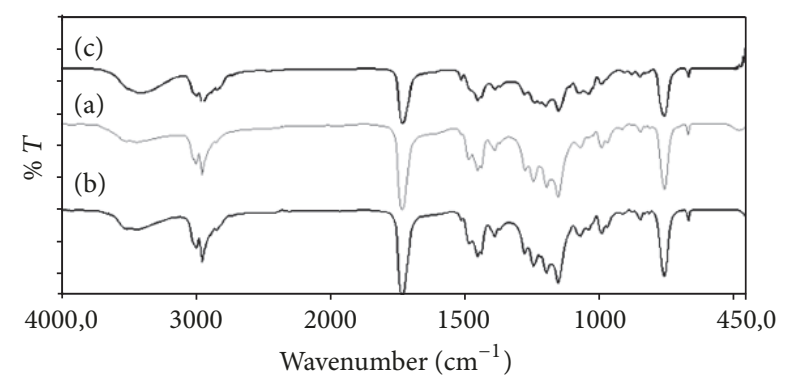

Figure 5: FT-IR spectra of (a) P(DEAMSt0.11-co-MMA), (b) $\mathrm{P}$ (DEAMSt0.19-co-MMA), and (c) P(DEAMSt0.30-co-MMA).

TABLE 1: The average molecular weights and polydispersities of P(DEAMSt-co-MMA).

\begin{tabular}{lccc}
\hline Copolymer & $M_{n}$ & $M_{w}$ & $\mathrm{HI}\left(=M_{w} / M_{n}\right)$ \\
\hline P(DEAMSt0.11-co-MMA) & $7.63 \times 10^{3}$ & $7.73 \times 10^{3}$ & 1.02 \\
P(DEAMSt0.19-co-MMA) & $7.91 \times 10^{3}$ & $8.01 \times 10^{3}$ & 1.01 \\
P(DEAMSt0.30-co-MMA) & $7.69 \times 10^{3}$ & $7.78 \times 10^{3}$ & 1.01 \\
\hline
\end{tabular}

3.2. Thermal Characterization. The glass transition temperatures $\left(T_{g}\right)$ for different combinations of P(DEAMSt-coMMA) and P(DEAMSt) were determined from the differential scanning calorimetry (DSC) curves (Figure 7) and the $T_{g}$ values of the obtained homopolymer and copolymers are given in Table 2. The DSC measurements were carried out at $200^{\circ} \mathrm{C}$ under $\mathrm{N}_{2}$ flow with a heating rate of $20^{\circ} \mathrm{C} / \mathrm{min}$. All the copolymers and homopolymer showed a single transition and have homogeneous phase distribution. The glass transition temperature $\left(T_{q}\right)$ of $\mathrm{P}(\mathrm{DEAMSt})$ was measured at $80^{\circ} \mathrm{C}$. The $T_{g}$ values of P(DEAMSt0.11-co-MMA), P(DEAMSt0.19-coMMA), and P(DEAMSt0.30-co-MMA) were measured as 113, 105 , and $93^{\circ} \mathrm{C}$, respectively. The $T_{g}$ values of the copolymers containing DEAMSt are $113^{\circ} \mathrm{C}$ for P(DEAMSt0.11-co-MMA) and $93^{\circ} \mathrm{C}$ for $\mathrm{P}(\mathrm{DEAMSt} 0.30$-co-MMA). The increasing amount of DEAMSt units in the copolymer decreased the $T_{g}$ value and the $T_{g}$ value was getting close to that of $\mathrm{P}(\mathrm{DEAMSt})$ $\left(T_{g}=80^{\circ} \mathrm{C}\right)$. In this case, the increase of the DEAMSt units in the structure of the copolymer increased the chain flexibility and free volumes and the $T_{g}$ decreased. This is probably due to a group with bulking such as diethanol amine on the DEAMSt moieties [3]. The revealing results consisted of the results recorded in the literature $[3,13]$.

To examine the thermal behaviors of the P(DEAMSt) and copolymers, the TGA curves (Figure 8) were recorded. For this purpose, the TGA measurements were carried out by heating up to $500^{\circ} \mathrm{C}$ under $\mathrm{N}_{2}$ flow at $10^{\circ} \mathrm{C} / \mathrm{min}$ heating rate, and the results are given in Table 2. In Table 2 have been submitted the initial and final decomposition temperatures, the temperature at $50 \%$ weight loss, the $T_{g}$ value, and $\%$ residue at $500^{\circ} \mathrm{C}$ for the polymers.

The thermal degradation behavior of all polymers showed single stage. The initial decomposition temperatures of the $\mathrm{P}$ (DEAMSt-co-MMA) with various DEAMSt contents of 0.11 , 0.19 , and 0.30 were measured as 213,219 , and $228^{\circ} \mathrm{C}$ and the final decomposition temperatures were 409,410 , and $400^{\circ} \mathrm{C}$, respectively. According to the obtained data, the thermal stability increased by the increasing amount of DEAMSt units in the copolymer structure. The decomposition temperatures at $50 \%$ weight loss were measured as 338,329 , and $339^{\circ} \mathrm{C}$, and it was obvious that this value increased by the increasing amount of DEAMSt units. The highest \% residue amount at $500^{\circ} \mathrm{C}$ was observed for the $\mathrm{P}(\mathrm{DEAMSt})$. The initial and final decomposition temperatures of the homopolymer are higher than those of the copolymers. All these results indicate the high thermal stabilities of P(DEAMSt). The weight reductions seen in the TGA curves are resulting from some impurities, from solvent residue, and from moisture although polymers are dried for long durations.

3.3. Adsorption Studies of Copolymers. The dye uptake properties of the modified DEAMSt with MMA in different combinations were investigated. Bromocresol green (BCG) was used as an adsorbent. The dye uptake properties were 


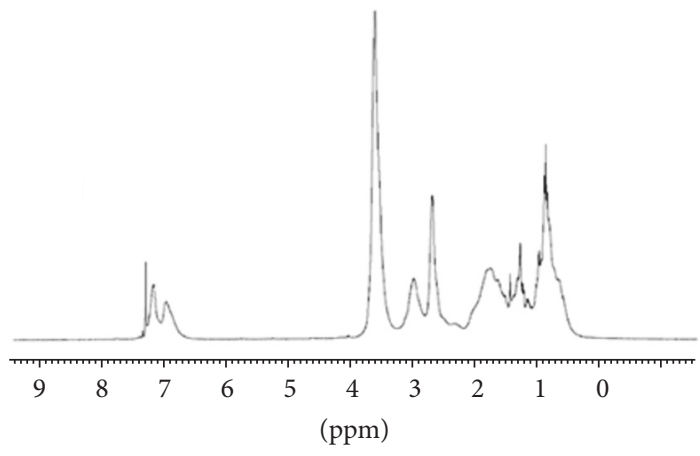

(a)

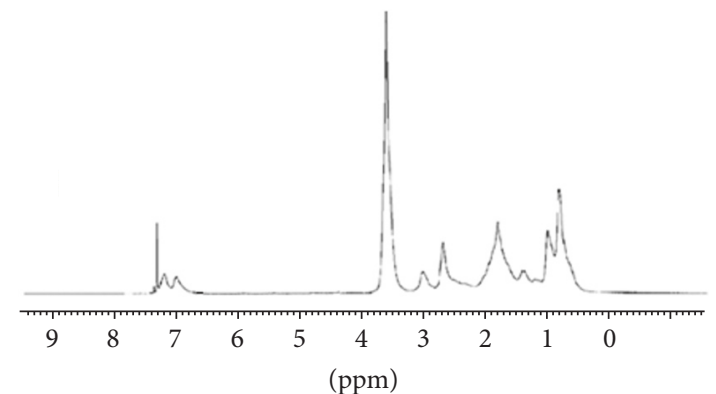

(b)

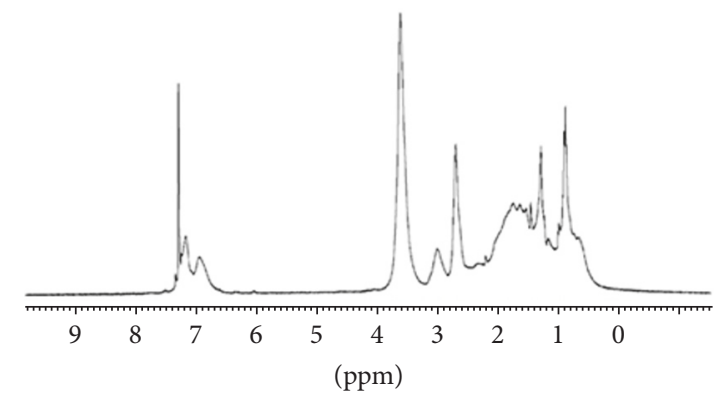

(c)

Figure 6: ${ }^{1}$ H-NMR spectra of (a) P(DEAMSt0.11-co-MMA), (b) P(DEAMSt0.19-co-MMA), and (c) P(DEAMSt0.30-co-MMA).

TABLE 2: TGA and DSC results of the P(DEAMSt) and P(DEAMSt-co-MMA).

\begin{tabular}{lccccc}
\hline Polymer systems & $T_{g}\left({ }^{\circ} \mathrm{C}\right)$ & $\begin{array}{c}\text { Initial } \\
\text { decomposition } \\
\text { temp. }\left({ }^{\circ} \mathrm{C}\right)\end{array}$ & $\begin{array}{c}\text { Final decomposition } \\
\text { temp. }\left({ }^{\circ} \mathrm{C}\right)\end{array}$ & $\begin{array}{c}50 \% \text { weight loss temp } \\
\left({ }^{\circ} \mathrm{C}\right)\end{array}$ & $\begin{array}{c}(\%) \text { residue at 500 } \\
\left({ }^{\circ} \mathrm{C}\right)\end{array}$ \\
\hline P(DEAMSt0.11-co-MMA) & 113 & 213 & 409 & 338 & 8 \\
P(DEAMSt0.19-co-MMA) & 105 & 219 & 410 & 329 & 14 \\
P(DEAMSt0.30-co-MMA) & 93 & 228 & 400 & 339 & 7 \\
P(DEAMSt) & 80 & 229 & 410 & 340 & 19 \\
\hline
\end{tabular}

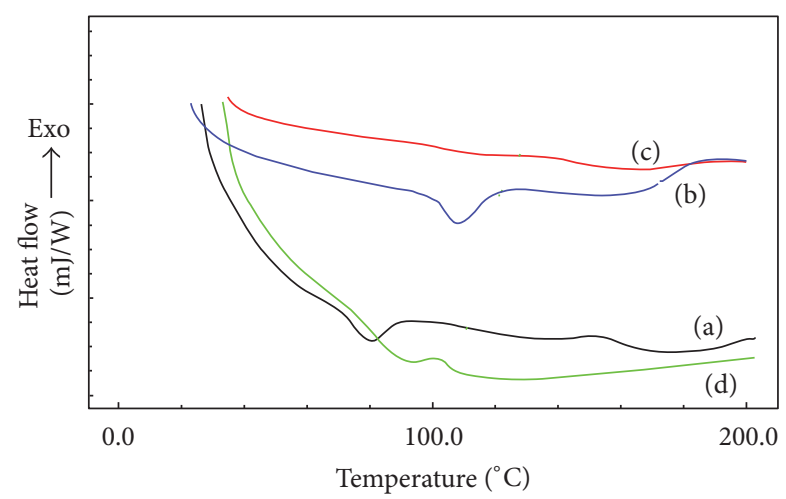

Figure 7: DSC curves of (a) P(DEAMSt), (b) P(DEAMSt0.11-coMMA), (c) P(DEAMSt0.19-co-MMA), and (d) P(DEAMSt0.30-coMMA).

studied at room temperature $(298 \mathrm{~K})$ and at $\mathrm{pH}=3.8-5.5$. For this purpose, the dye solution was prepared by dissolving

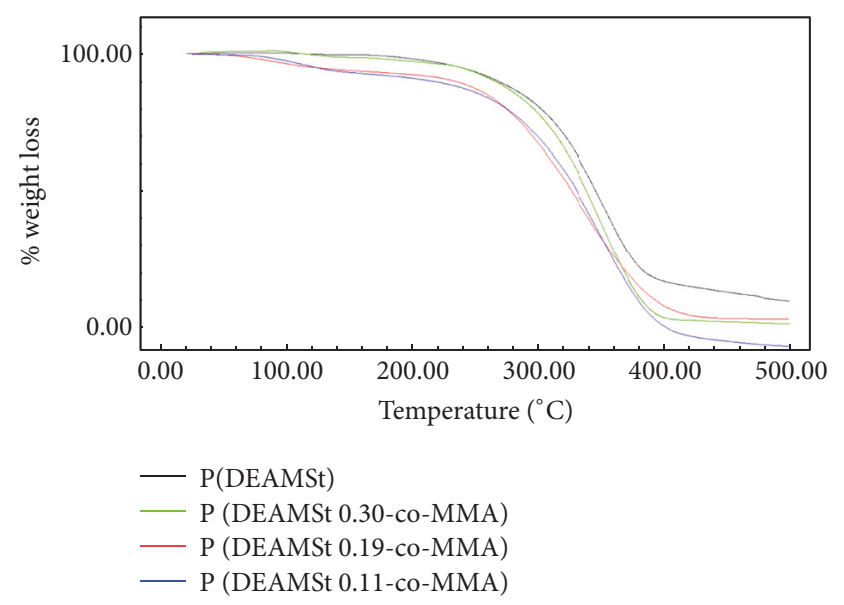

FIgURE 8: TGA curves of P(DEAMSt) and P(DEAMSt-co-MMA).

BCG $(0.035 \mathrm{~g})$ in $500 \mathrm{~mL}$ water. Then, in the dye adsorption experiments, $0.1 \mathrm{~g}$ of polymer samples was added onto $5 \mathrm{~mL}$ 
portions of BCG solution and the absorbance was measured at different times and temperatures $\left(25,45,55\right.$, and $\left.65^{\circ} \mathrm{C}\right)$ by diluted samples periodically. The absorbance measurements were carried out by UV-visible spectrophotometer at $\lambda_{\max }=$ $350 \mathrm{~nm}$. The calibration curve was prepared previously and the amount of BCG absorbed on the polymers was calculated by the following equation [14].

The dye adsorption $\left(Q_{e}\right)=\frac{\left(C_{o}-C\right) \cdot V \cdot K}{W g}$.

$C_{o}$ is the initial concentration of dye solution.

$K$ is the amount of dilution.
$C$ is the final concentration of the dye solution.

$V$ is the volume of dye solution.

$W g$ is the weight of polymer.

To determine the physical and chemical adsorption amounts, the painted polymers were washed twice with $5 \mathrm{~mL}$ of ethyl alcohol. The absorption was measured by UV-visible spectrophotometer at $\lambda_{\max }=350 \mathrm{~nm}$. The dye amount was found by utilizing the calibration curve. The amount of substance extracted by ethylalcohol, the physical and chemical adsorption quantities, was determined after the washing process.

$$
\begin{array}{r}
\text { Amount of substance extracted by alcohol (physical adsorption) }=\frac{C \cdot V \cdot K}{W g}, \\
\text { Chemical adsorption (mg dye/g polymer) }=C_{t}-C_{f} .
\end{array}
$$

$C$ is the concentration of dye solution.

$V$ is the volume of alcohol used for washing.

$C_{t}$ is the total amount of dye that holds the polymer.

$C_{f}$ is the alcohol outgoing amount of dye.

Then, the adsorption kinetics of the P(DEAMSt-coMMA) with different compositions were investigated. The following equations were used to determine the adsorption rates [15]. tion) is

First-order rate adsorption equation (Lagergren equa-

$$
\log \left(g_{e}-g_{t}\right)=\log g_{e}-\frac{k_{1} \cdot t}{2,303}
$$

Pseudo-second-order rate adsorption equation is

$$
\frac{1}{q_{t}}=\frac{1}{k_{2} \cdot q_{e}^{2}}+\frac{1}{q_{e}} \cdot t .
$$

$k_{1}$ is the first-order adsorption rate constant $\left(\right.$ time $\left.^{-1}\right)$. $k_{2}$ is the pseudo-second-order adsorption rate constant (mg/g.time).

$q_{e}$ is the amount of adsorbed substance at equilibrium (mg/g).

$q_{t}$ is the amount of the adsorbed substance at any time.

The obtained $\log \left(q_{e}-q_{t}\right)$ and $t / q_{t}$ values at different times $(t)$ were calculated graphically to find the $k_{1}$ and $k_{2}$ values.

The change in the dye uptake (BCG) of the copolymers versus time is seen in Figure 9. As it can be seen in the graphs, the BCG uptake capacity of the copolymers was almost fixed in 60 minutes.
Then, the dye uptake capacity of the copolymers was examined at different temperatures for the constant duration of 30 minutes. The results were given in Table 3.

As seen in Table 3, the dye uptake capacities for $\mathrm{P}$ (DEAMSt0.11-co-MMA) at different temperatures such as 25, 45, 55, and $65^{\circ} \mathrm{C}$ were calculated as 28.3, 20.8, 20.5, and $20.4 \mathrm{mg}$ dye/g polymer, respectively. According to these results, the dye uptake capacity values decreased with increasing temperature. Because the adsorption process usually is an exothermic phenomenon, the adsorption increases with decreasing in temperature. The similar results were observed for the other two copolymers and this indicates that the process is physical adsorption.

Then, the dye uptaking copolymers were washed twice with $10 \mathrm{~mL}$ of ethylalcohol and the dye amounts in alcohol were measured. The dye quantities of alcohol were determined by UV device at $\lambda_{\max }=350 \mathrm{~nm}$ at different temperatures such as 25,45 , and $65^{\circ} \mathrm{C}$. The physical and chemical adsorption values were determined using (3). The obtained results are given in Table 4 . As can be seen from Table 4, the physical adsorption process occurred for the copolymers with different combinations.

The adsorption kinetics are calculated according to (4) and (5). The adsorption of BCK onto P(DEAMSt-co-MMA) was studied at room temperature $(298 \mathrm{~K})$. The $k_{1}\left(\mathrm{~min}^{-1}\right)$ (indicating the first-order kinetics) and $k_{2}$ ( $\mathrm{mg} / \mathrm{g}$ time) (indicating the pseudo-second-order kinetics) values were determined from the graph in Figures 10-12.

The kinetics parameters for the adsorption of BCG onto copolymers are given in Table 5 . As seen in Table 5 , the $R^{2}$ correlation coefficients were found $0.90,0.93$, and 0.85 for $11 \%$ DEAMSt, 19\%DEAMSt, and 30\%DEAMSt, respectively, for the first-order kinetics; and the $R^{2}$ values were found as $0.99,0.99$, and 1.00 for $11 \%$ DEAMSt, $19 \%$ DEAMSt, and $30 \%$ DEAMSt for pseudo-second-order kinetics, respectively. These results showed that the adsorption was followed for 
TABLE 3: The dye uptake amount of P(DEAMSt -co-MMA) in different temperatures.

\begin{tabular}{lcccccccccc}
\hline Polymer & \multicolumn{3}{c}{ P(DEAMSt0.11-co-MMA) } & \multicolumn{3}{c}{ P(DEAMSt0.19-co-MMA) } & \multicolumn{3}{c}{ P(DEAMSt0.30-co-MMA) } \\
\hline $\begin{array}{l}\text { Temperature }\left({ }^{\circ} \mathrm{C}\right) \\
\begin{array}{l}\text { Dye adsorption } \\
\text { (mg dye/g polymer) }\end{array}\end{array}$ & 25 & 45 & 55 & 65 & 25 & 45 & 55 & 65 & 25 & 45 \\
\hline
\end{tabular}

TABLE 4: The physical and chemical adsorption amount of P(DEAMSt-co-MMA).

\begin{tabular}{|c|c|c|c|c|c|c|c|c|c|}
\hline \multirow{2}{*}{$\frac{\text { Polymer }}{\text { Temperature }\left({ }^{\circ} \mathrm{C}\right)}$} & \multicolumn{3}{|c|}{ P(DEAMSt0.11-co-MMA) } & \multicolumn{3}{|c|}{ P(DEAMSt0.19-co-MMA) } & \multicolumn{3}{|c|}{ P(DEAMSt0.30-co-MMA) } \\
\hline & 25 & 45 & 65 & 25 & 45 & 65 & 25 & 45 & 65 \\
\hline $\begin{array}{l}\text { Alcohol outgoing amount of dye } \\
\text { (mg dye/10 mL alcohol) physical } \\
\text { ads. }\end{array}$ & 12.8 & 20.3 & 20.7 & 17.0 & 19.6 & 19.8 & 17.6 & 19.5 & 19.7 \\
\hline $\begin{array}{l}\text { Alcohol exceeding amount of dye } \\
\text { (mg dye } / 10 \mathrm{~mL} \text { alcohol) chemical } \\
\text { ads. }\end{array}$ & 15.5 & 0.4 & 0.3 & 7.1 & 1.9 & 1.5 & 5.9 & 2.1 & 1.7 \\
\hline$\%$ physical adsorption & 45.2 & 98.1 & 98.5 & 70.5 & 91.1 & 92.9 & 74.0 & 90.2 & 92.1 \\
\hline$\%$ chemical adsorption & 54.8 & 1.93 & 1.42 & 29.5 & 8.83 & 7.1 & 25.1 & 9.7 & 7.9 \\
\hline
\end{tabular}

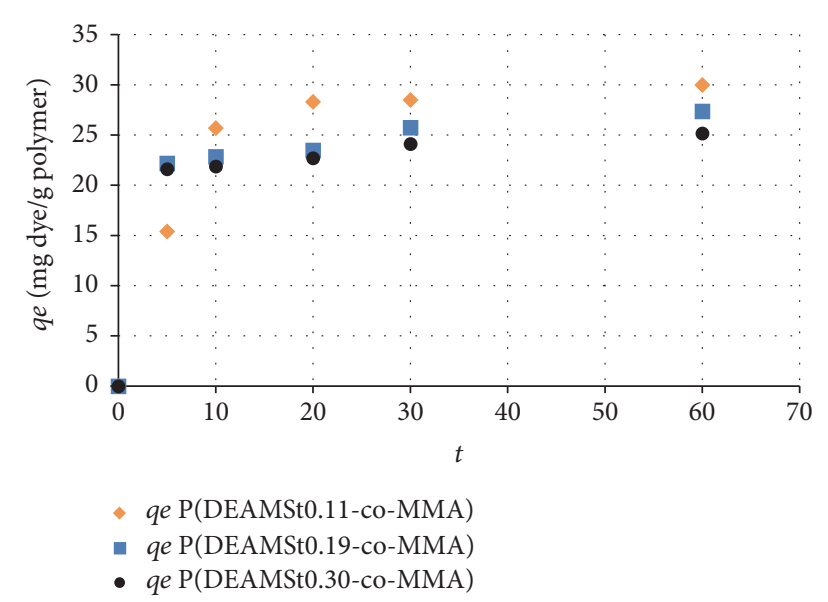

Figure 9: The time change depending on dye uptake quantity of P(DEAMSt-co-MMA).

the pseudo-second-order kinetics models $[12,16]$. Also, $q_{e}$ values in the table and the fixed amounts of dye adsorption are showed [17]. This is an indication of experimental and theoretically pseudo-second-order compliance $[17,18]$.

3.4. Dielectrical Behavior and Conductivity of P(DEAMStco-MMA). It is known that the change in the dielectric properties of the polymers is due to the electronic, ionic, and molecular polarizability. These properties are related to the physical and chemical structure of the polymer. The electrical properties of the polymers change with frequency. In order to determine the electrical properties of the prepared P(DEAMSt0.11-co-MMA) and P(DEAMSt0.19-coMMA), the dielectric behaviors and conductivity measurements were carried out at various temperature and frequency values.

The dielectric measurements of the copolymers were investigated by using the LCR Meter Impedance Analyzer device. For this purpose, $0.1 \mathrm{~g}$ of copolymer was kept under four tons of pressure and transformed to disk. Its thickness was measured and the disk surfaces were coated with silver paste. The dielectric constants were calculated using the following formula $[10,19]$.

$$
\varepsilon^{\prime}=C_{p} \cdot \frac{d}{\varepsilon_{o} \cdot A} .
$$

$C_{p}$ is the parallel capacitance values.

$d$ is the thickness of the polymer sample.

$\varepsilon_{o}$ is the permittivity in free space $\varepsilon_{o}=8,854 \times$ $10^{-12} \mathrm{~F} / \mathrm{m}$.

$\varepsilon^{\prime}$ is the dielectric constant.

The dielectric losses factor in the copolymer were calculated by the equation

$$
\varepsilon^{\prime \prime}=\mathrm{DF} \cdot \varepsilon^{\prime}
$$

The capacitance measurements were performed at different frequencies ( $100 \mathrm{~Hz}$ to $2 \mathrm{kHz}$ ) and temperatures (from 298 to $423 \mathrm{~K}$ ) by impedance analyzer (Figures 13-16).

As seen from the graphs, the dielectrical constants $\left(\varepsilon^{\prime}\right)$ decreased by increasing frequency (Figure 13). It was observed that the capacitance values of the copolymers increased as the frequency increased, and they started to decrease after a maximum exceeded and they remained stable at high frequencies $[20,21]$. It can be said that this probably is an indication of polarizability of the interface surfaces. When the electric field is applied, moving surface loads occur on the surface of copolymers. As the electric field is applied, these loads cause a superficial polarization by cumulating on the dielectric surface $[22,23]$. In this case, the increase in the frequency causes a decrease in the dielectric constant. The dielectric loss factor $\left(\varepsilon^{\prime \prime}\right)$ of the copolymers decreased as the 


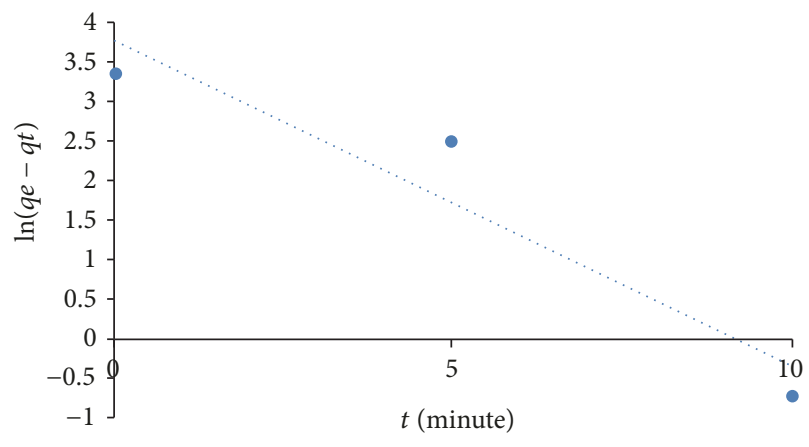

(a)

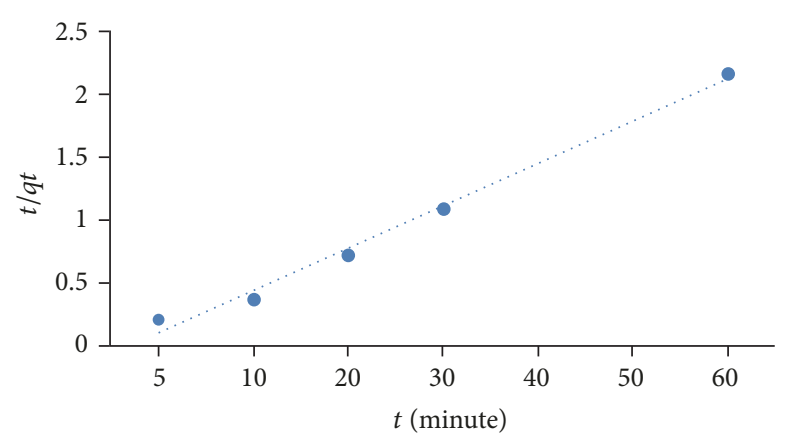

(b)

FIgURE 10: The adsorption kinetics of P(DEAMSt0.11-co-MMA): (a) first-order and (b) pseudo-second-order.

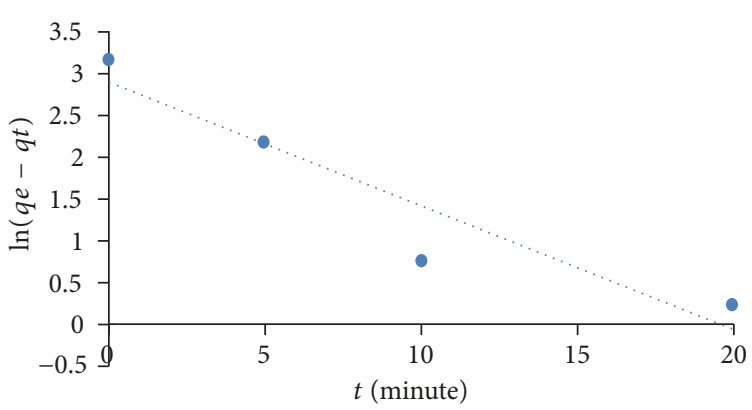

(a)

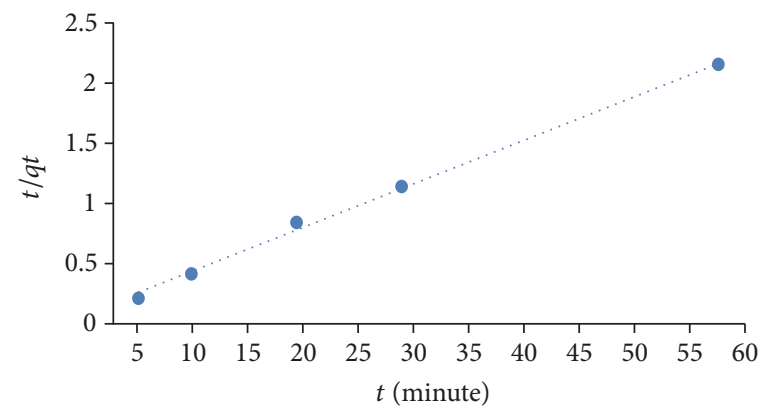

(b)

Figure 11: The adsorption kinetics of P(DEAMSt0.19-co-MMA): (a) first-order and (b) pseudo-second-order.

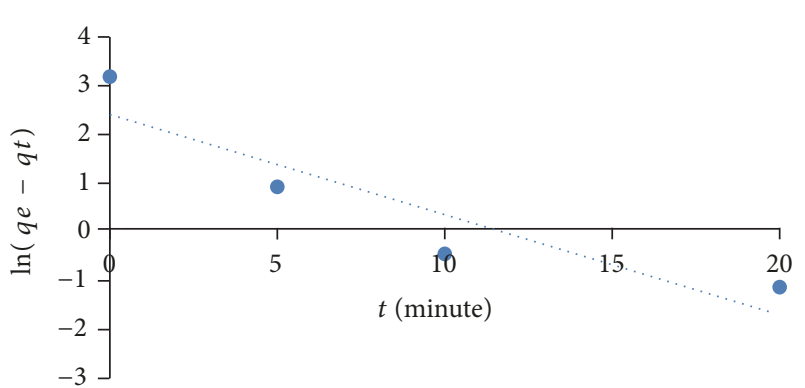

(a)

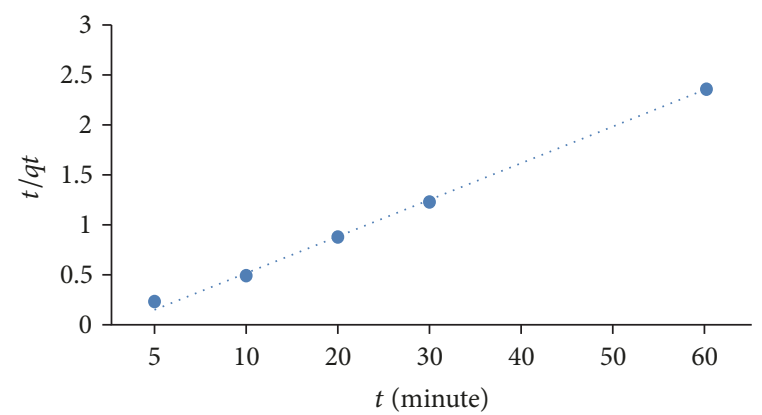

(b)

FIgure 12: The adsorption kinetics of P(DEAMSt0.30-co-MMA): (a) first-order and (b) pseudo-second-order.

frequency increased $[22,24]$ (Figure 14). The reason for the reduction in the frequency of the dielectric loss factor $\left(\varepsilon^{\prime \prime}\right)$ values can be due to the free movement of molecules.

The dielectric constant $\left(\varepsilon^{\prime}\right)$ and dielectric loss factor $\left(\varepsilon^{\prime \prime}\right)$ in both compositions (11 and 19\%) of copolymers changed with temperature (Figures 15 and 16). As seen from the graphs, the $\left(\varepsilon^{\prime}\right)$ and $\left(\varepsilon^{\prime \prime}\right)$ values of the copolymers increased with temperature and at high temperatures, and they increased more rapidly due to the segmental mobility and dipoles [25]. As the polymers are stationary and fixed under the glass transition temperature, when an electric field is applied to the polymer, the polymer chain movements increase as the polymer free volumes increase the glass transition temperature and a space occurs. In this case, the dielectric constant and dielectric losses factor increase by the temperature $[3,23,25]$.

The dielectric constant, dielectric loss factor, and conductivity of the obtained P(DEAMSt-co-MMA) were measured at $1 \mathrm{kHz}$ at room temperature. The results are summarized in Table 6.

As shown in Table 6 , the $\varepsilon^{\prime}, \varepsilon^{\prime \prime}$, and conductivity $\sigma$ values of the copolymers increased as the percent amount of DEAMSt units increased. The dielectric constants of the $\mathrm{P}$ (DEAMSt0.11-co-MMA) and P(DEAMSt0.19-co-MMA) were found as 3.15 and 6.55 , respectively. The dielectric loss factors of copolymer systems showed a similar behavior. 
TABLE 5: The kinetic parameters for BCK on P(DEAMSt-co-MMA).

\begin{tabular}{lccccc}
\hline \multirow{2}{*}{ Polymer } & \multicolumn{3}{c}{ First-order-kinetics parameters } & \multicolumn{3}{c}{ Pseudo-order-kinetics parameters } \\
& $k_{1}$ & $R^{2}$ & $q e$ & $k_{2}$ & $R^{2}$ \\
\hline P(DEAMSt0.11-co-MMA) & 0.925 & 0.90 & 5.12 & 0.016 & 0.99 \\
P(DEAMSt0.19-co-MMA) & 0.334 & 0.93 & 8.51 & 0.022 & 0.99 \\
P(DEAMSt0.30-co-MMA) & 0.483 & 0.85 & 2.51 & 0.12 & 29.85 \\
\hline
\end{tabular}

TABLE 6: The dielectric constant, dielectric losses factor, and conductivity values of P(DEAMSt-co-MMA).

\begin{tabular}{|c|c|c|c|c|}
\hline Polymer & Dielectric constant $\left(\varepsilon^{\prime}\right)$ & Dielectric loss factor $\left(\varepsilon^{\prime \prime}\right)$ & Conductivity $(\mathrm{S} / \mathrm{cm})(\sigma)$ & $E_{a}(\mathrm{eV})$ \\
\hline P(DEAMSt 0,11-co-MMA) & 3.15 & 0.097 & $5.48 \times 10^{-9}$ & 0.11 \\
\hline P(DEAMSt 0,19-co-MMA) & 6.55 & 0.301 & $1.71 \times 10^{-8}$ & 0.08 \\
\hline
\end{tabular}

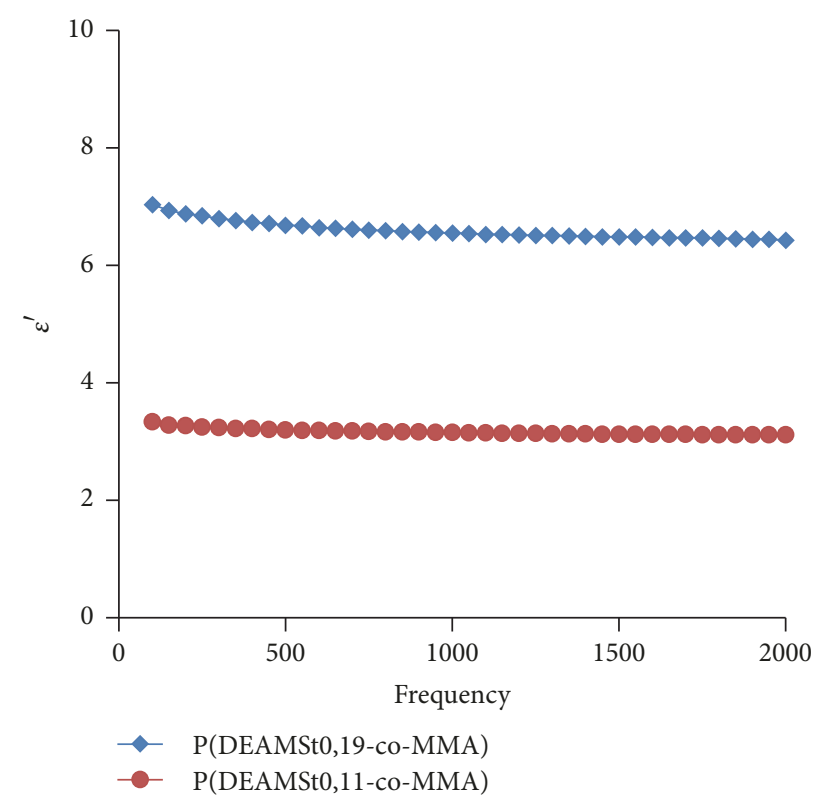

FIGURE 13: The graph of the dielectric constants change by the frequency of P(DEAMSt0.11-co-MMA) and P(DEAMSt0.19-coMMA).

The conductivities of the $\mathrm{P}(\mathrm{DEAMSt} 0.11-\mathrm{co}-\mathrm{MMA})$ and $\mathrm{P}\left(\right.$ DEAMSt0.19-co-MMA) were $\sigma=5.48 \times 10^{-9} \mathrm{~S} / \mathrm{cm}$ and $\sigma$ $=1.71 \times 10^{-8} \mathrm{~S} / \mathrm{cm}$, respectively. According to the obtained results, the dielectric constant, dielectric loss factor, and conductivity values increased with the increase in DEAMSt units depending on copolymer compositions.

The conductivity values of the P(DEAMSt-co-MMA) with different combination were determined from the changes in frequency and temperature.

The " $\sigma_{p}$ " values of the conductance parameters were calculated using the following equation:

$$
\sigma_{p}=G \cdot \frac{d}{A},
$$

where $G$ is the conductance, $d$ is the thickness, and $A$ is the sample space.

The $\log \sigma$ values are plotted against frequency and temperature (Figures 17 and 18). As seen from the graphs,

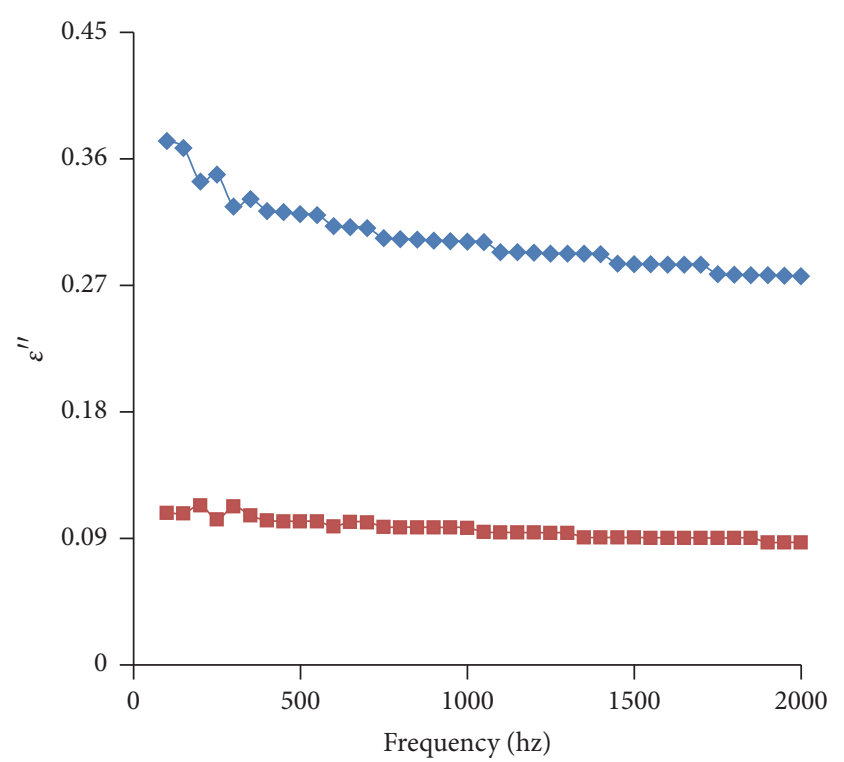

(DEAMSt0,19-co-MMA)

$\rightarrow \mathrm{P}(\mathrm{DEAMSt} 0,11-\mathrm{co}-\mathrm{MMA})$

FIgURE 14: The graph of the dielectric loss factor change by the frequency of $\mathrm{P}$ (DEAMSt0.11-co-MMA) and P(DEAMSt0.19-coMMA).

the electrical conductivity increased with temperature and frequency.

It can be stated that the necessary activation energy for the activity of the charge carrier ions is dependent on temperature [25]. In this case, the mobility of the polymer has sufficient activation energy for the activity of the charge carrier ions as the temperature increases [25]. The mobility of the polymer chain with increasing temperature leads to increased free volume in the polymer and this increases the polarization and causes an increase in conductivity [26]. According to these results, the electrical conductivities of the copolymers are sensitive to an increase in the frequency and temperature. In addition, the dielectric constant and conductivity showed a sudden increase in increasing temperature at any certain point. It was considered that this increase is due to the increase in the free volume due to the structures of the polymer molecules [27]. 


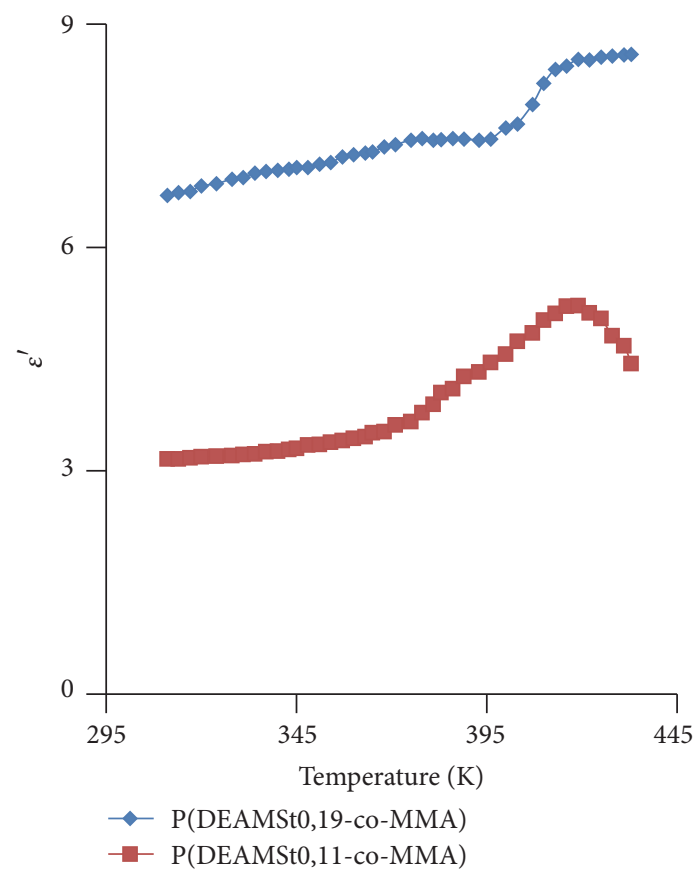

FIGURE 15: The change of the dielectric constants versus temperature for P(DEAMSt0.11-co-MMA) and P(DEAMSt0.19-co-MMA).

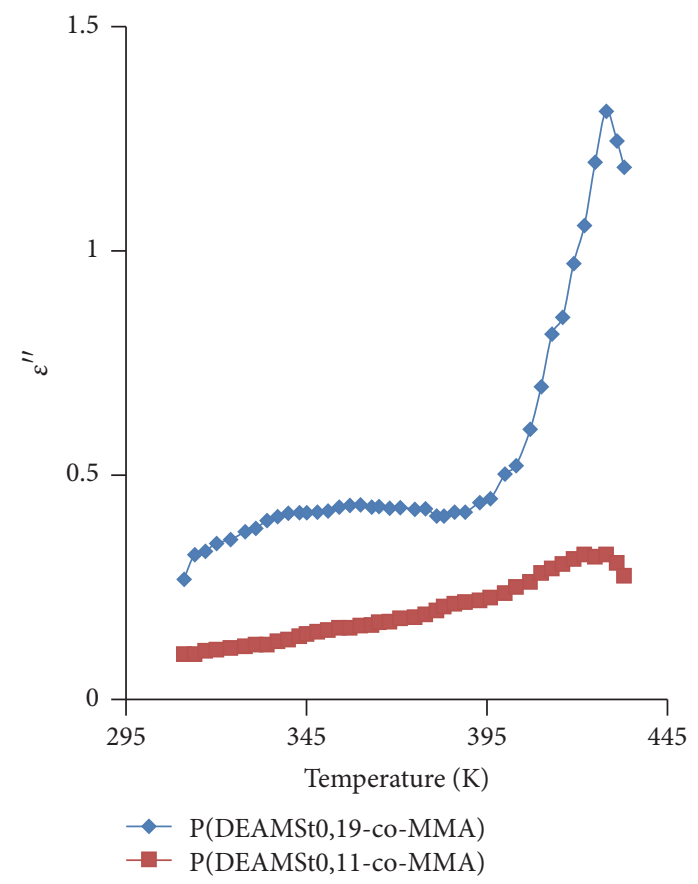

Figure 16: The graph of the dielectric loss factor change by the temperature for P(DEAMSt0.11-co-MMA) and P(DEAMSt0.19-coMMA).

The activation energy values were calculated using the Arrhenius equation (9) which relates the conductivity to temperature exponentially [28].

$$
\sigma=\sigma_{o} e^{-E_{a} / k T}
$$

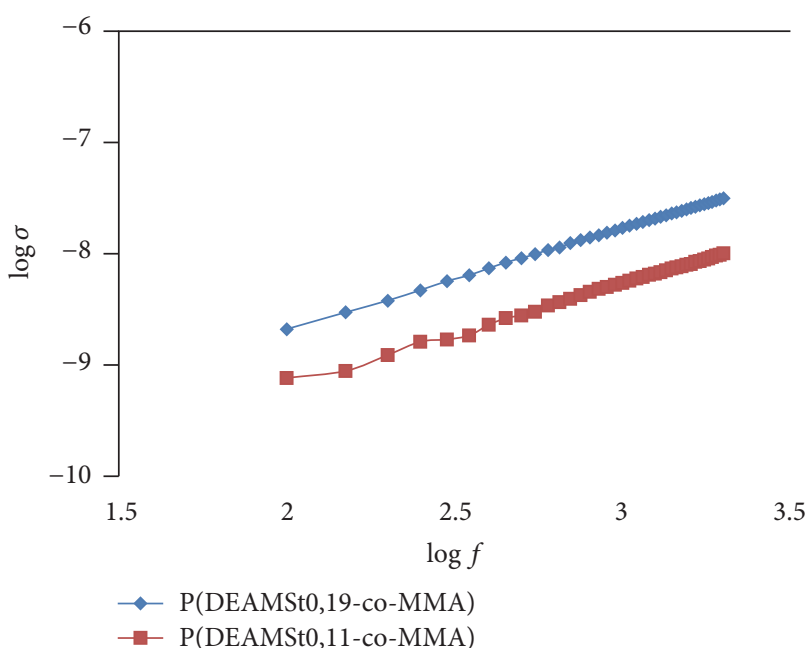

FIGURE 17: The graph of the conductivity $(\log \sigma)$ change with frequency for $\mathrm{P}$ (DEAMSt0.11-co-MMA) and P(DEAMSt0.19-coMMA).

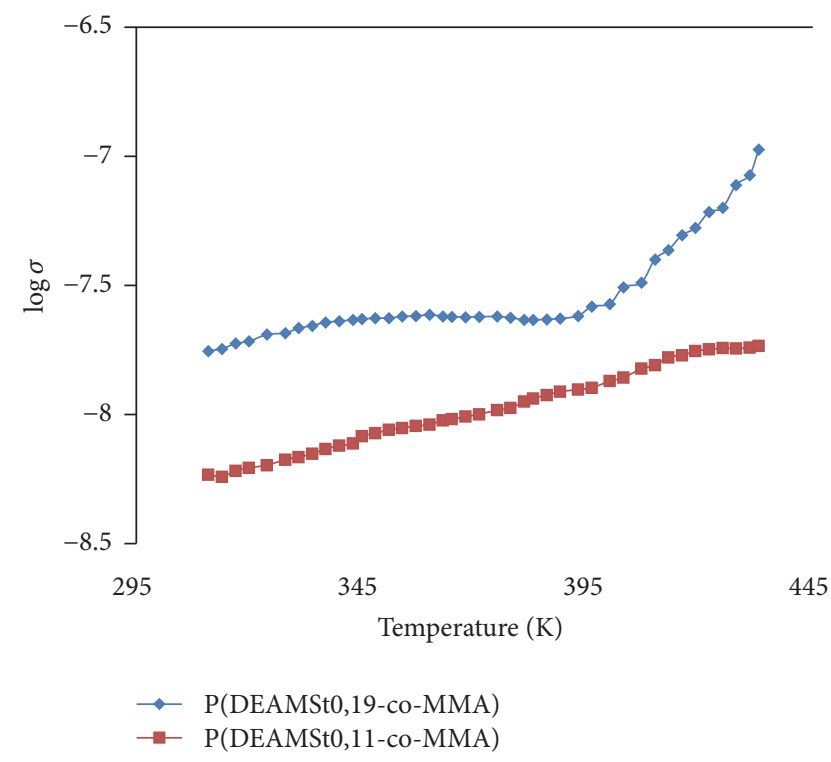

FIgURE 18: The graph of the conductivity $(\log \sigma)$ change with temperature for P(DEAMSt0.11-co-MMA) and P(DEAMSt0.19-coMMA).

where $\sigma$ is conductivity $(\mathrm{S} / \mathrm{cm}), \sigma_{o}$ is constant, $E_{a}$ is activation energy (eV), $k$ is Boltzmann constant, and $T$ is absolute temperature (K) (Figures 19(a) and 19(b)). The activation energies were calculated from the slopes of the graphs for two different copolymer systems. Here, $E_{a}$ is the activation energy of ionic conductions and the energy barrier for the ionic transport. The energy barrier for the ionic transport reduces as temperature rises and this leads to an increase in the ionic conductivity [29]. The thermal activation energy is inversely proportional to the electrical conductivity and the temperature dependence of the electrical conductivity shows that the conductivity increases with temperature [30]. The obtained data were given in Table 6 . The activation 


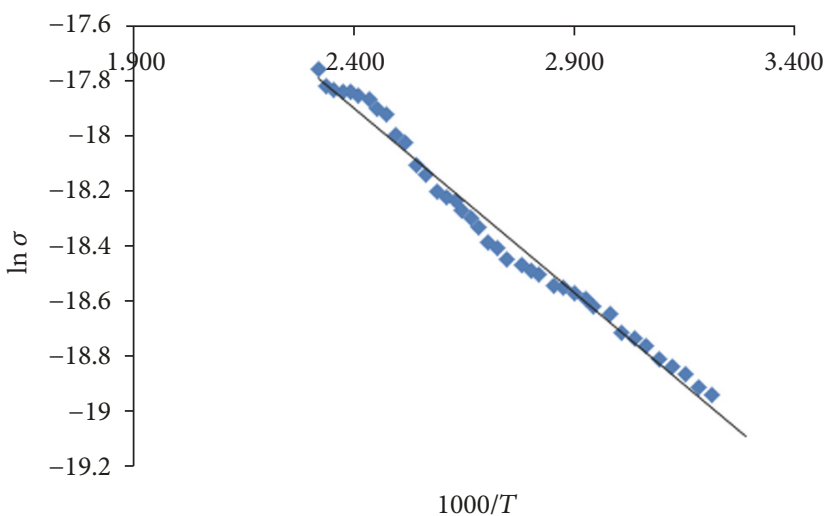

(a)

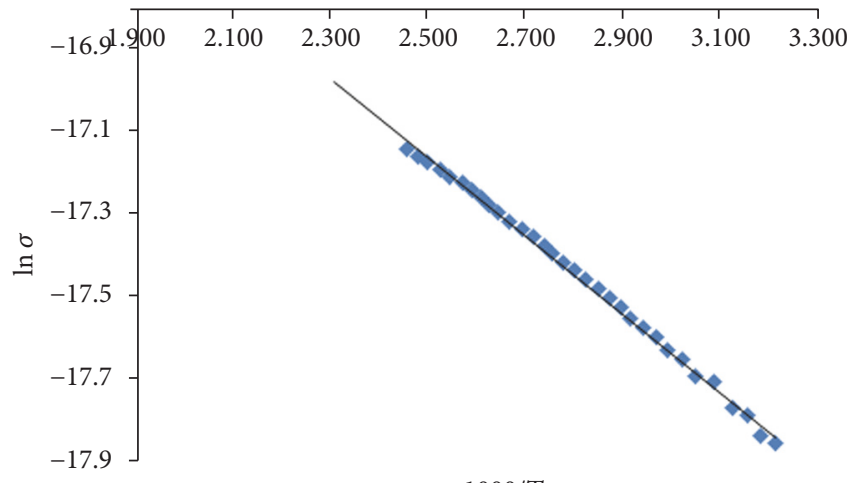

$1000 / T$

(b)

FIGURE 19: The graph of the conductivity $(\ln \sigma)$ with 1000/T temperature for (a) P(DEAMSt0.11-co-MMA) and (b) P(DEAMSt0.19-co-MMA).

energy, as shown in Table 6, decreased with the increasing amount of DEAMSt. This effect is based on the presence of polar groups. When the activation energy decreases, the number of carrier ions increases. The activation energies of the $\mathrm{P}$ (DEAMSt0.19-co-MMA) polymer are lower than those of $\mathrm{P}$ (DEAMSt0.11-co-MMA) at higher temperatures. The activation energy of the copolymer including 0.19DEAMSt in the polymer chain decreased. The number of transported ions and the conductivity increased with decreasing activation energy [27] and the super-ionic structure was sustained in high-temperature region. This situation is in accordance with the results obtained in the previous literature [31,32]. Furthermore, it was considered that electronic and polar relaxation occurred when the activation energy values are lower [33].

\section{Conclusions}

The 4-diethanolaminomethyl styrene, DEAMSt, was prepared by the modification of 4-chloromethyl styrene with diethanolamine. A series copolymer system in different combinations $(0.11,0.19$, and 0.30$)$ of the modified DEAMSt and methyl methacrylate monomer was prepared by free radical polymerization method. The FT-IR and ${ }^{1} \mathrm{H}-\mathrm{NMR}$ techniques confirmed the structures of DEAMSt and P(DEAMSt-coMMA). The thermal behaviors and the glass transition temperatures were determined by TGA and DSC. The dye uptake properties (BCG) of the obtained copolymers were investigated. The results showed that the adsorption kinetics of the P(DEAMSt-co-MMA) in different combinations was modeled by the pseudo-second-order kinetics and it was found to be a physical adsorption. The dielectric constants $\left(\varepsilon^{\prime}\right)$ were found as $0.11 \varepsilon^{\prime}=3.15 ; 0.19 \varepsilon^{\prime}=6.55$ at $1 \mathrm{kHz}$ depending on the compositions of the copolymers. According to the obtained results, the $\varepsilon^{\prime}, \varepsilon^{\prime \prime}$, and $\sigma$ values in the copolymers increased with the increase in the DEAMSt units; this is explained by the increase of the $\mathrm{OH}$ groups in the copolymer chain and the increase of the polarity. The dielectric constant, dielectric loss factor, and conductivity increased by increasing temperature. The DEAMSt0.19 possesses the highest conductivity, low activation energy, high amorphous structure, and high thermal stability. There is a relationship between the chemical structure of the polymer and another properties like the mechanical and thermal ones, which is very important for potential applications.

\section{Conflicts of Interest}

The authors declare that they have no conflicts of interest.

\section{Acknowledgments}

The authors wish to thank FUBAP FF-13-22 for financial support of this project.

\section{References}

[1] M.-S. Gong and C.-W. Lee, "Humidity-sensitive properties of gel polyelectrolyte based on cross-linked copolymers containing both ammonium salt and amine function," Materials Chemistry and Physics, vol. 77, no. 3, pp. 719-725, 2003.

[2] S. G. Srivatsan, S. Verma, and M. Parvez, "4-Vinylbenzyl analogs of adenine and uracil: Reactive monomers for nucleobase polymeric resins," Acta Crystallographica Section C: Crystal Structure Communications, vol. 58, no. 7, pp. o378-o380, 2002.

[3] P. Seven, M. Coşkun, and K. Demirelli, "Synthesis and characterization of two-armed graft copolymers prepared with acrylate and methacrylate using atom transfer radical polymerization," Reactive and Functional Polymers, vol. 68, no. 5, pp. 922-930, 2008.

[4] M. W. Weimer, J. M. J. Fréchet, and I. Gitsov, "Importance of active-site reactivity and reaction conditions in the preparation of hyperbranched polymers by self-condensing vinyl polymerization: Highly branched vs. Linear poly[4(chloromethyl)styrene] by metal-catalyzed "living" radical polymerization," Journal of Polymer Science Part A: Polymer Chemistry, vol. 36, no. 6, pp. 955-970, 1998.

[5] S. G. Gaynor, S. Edelman, and K. Matyjaszewski, "Synthesis of branched and hyperbranched polystyrenes," Macromolecules , vol. 29, no. 3, pp. 1079-1081, 1996.

[6] M. Coşkun and M. M. Temüz, "Grafting of poly(styrene-co-pchloromethyl styrene) with ethyl methacrylate via atom transfer 
radical polymerization catalyzed by $\mathrm{CuCl} / 1,2$-dipiperidinoethane," Journal of Polymer Science Part A: Polymer Chemistry, vol. 41, no. 5, pp. 668-673, 2003.

[7] J. H. Truelsen, J. Kops, and W. Batsberg, "Synthesis by ATRP of triblock copolymers with densely grafted styrenic end blocks from a polyisobutylene macroinitiator," Macromolecular Rapid Communications, vol. 21, no. 2, pp. 98-102, 2000.

[8] K. M. Khot, P. K. K. S. Heer, R. B. Biniwale, and V. G. Gaikar, "Equilibrium adsorption studies of $\mathrm{CO}_{2}, \mathrm{CH}_{4}$, and $\mathrm{N}_{2}$ on amine functionalized polystyrene," Separation Science and Technology, vol. 49, no. 15, pp. 2376-2388, 2014.

[9] A. S. Haythem, A. A. S. Eman, C. Noureddine, and S. M. Mohammad, "Synthesis and adsorption properties, toward some heavy metal ions, of a new polystyrene-based terpyridine polymer," Journal of Applied Polymer Science, vol. 124, no. 4, pp. 2717-2724, 2012.

[10] M. Coşkun and P. Seven, "Synthesis, characterization and investigation of dielectric properties of two-armed graft copolymers prepared with methyl methacrylate and styrene onto PVC using atom transfer radical polymerization," Reactive and Functional Polymers, vol. 71, no. 4, pp. 395-401, 2011.

[11] S. İlboğa, Modification studies on styrene-p-chloromethyl styrene copolymers with amines. MSc Thesis, University of Firat, Turkey,2008.

[12] C. Sun, R. Qu, C. Ji et al., "Preparation and adsorption properties of crosslinked polystyrene-supported low-generation diethanolamine-typed dendrimer for metal ions," Talanta, vol. 70, no. 1, pp. 14-19, 2006.

[13] G. Barim, M. G. Yayla, and M. Degirmenci, "Copolymerization of cyclohexene-3-yl methyl methacrylate with styrene: Synthesis, characterization, monomer reactivity ratios, and thermal properties," Designed Monomers and Polymers, vol. 17, no. 7, pp. 610-616, 2014.

[14] M. M. Temüz, M. Coşkun, and A. Ölçücü, "Synthesis of graft copolymers of cellulose with 4-acryloylmorpholine, 2methacrylamidopyridine and N-phenylmethacrylamide, and determination of some sorption properties," Journal of Macromolecular Science, Part A Pure and Applied Chemistry, vol. 44, no. 9, pp. 947-952, 2007.

[15] G. Crini and P.-M. Badot, "Application of chitosan, a natural aminopolysaccharide, for dye removal from aqueous solutions by adsorption processes using batch studies: a review of recent literature," Progress in Polymer Science, vol. 33, no. 4, pp. 399447, 2008.

[16] F. Pishgar, H. Ahmad Panahi, A. A. Khodaparast Haghi, V. Motaghitalab, and A. H. Hasani, "Comparative Study on Adsorptive Characteristics of Diazinon and Chlorpyrifos from Water by Thermosensitive Nanosphere Polymer," Journal of Chemistry, vol. 2016, Article ID 8329650, 2016.

[17] K. Feng and G. Wen, "Absorbed $\mathrm{Pb}^{2+}$ and $\mathrm{Cd}^{2+}$ Ions in Water by Cross-Linked Starch Xanthate," International Journal of Polymer Science, vol. 2017, Article ID 6470306, 2017.

[18] B. Acemioǧlu, M. Ertas, M. H. Alma, and M. Usta, "Investigation of the adsorption kinetics of methylene blue onto cotton wastes," Turkish Journal of Chemistry, vol. 38, no. 3, pp. 454-469, 2014.

[19] S. Rajendran and M. Ramesh Prabhu, "Effect of different plasticizer on structural and electrical properties of PEMAbased polymer electrolytes," Journal of Applied Electrochemistry, vol. 40, no. 2, pp. 327-332, 2010.

[20] V. Rao, P. V. Ashokan, and M. H. Shridhar, "Studies of dielectric relaxation and a.c. conductivity in cellulose acetate hydrogen phthalate-poly(methyl methacrylate) blends," Materials Science and Engineering: A, vol. 281, no. 2, pp. 213-220, 2000.

[21] G. Iyibakanlar and A. Oktay, "Bazı polimerlerin dielektrik özelliklerinin frekansla değişimlerinin incelenmesi," Journal of Aeronautics and Space Technologie, vol. 3, no. 7, pp. 11-19, 2007.

[22] N. N. Beladakere, S. C. K. Misra, M. K. Ram et al., "Interfacial polarization in semiconducting polypyrrole thin films," Journal of Physics: Condensed Matter, vol. 4, no. 26, article no. 008, pp. 5747-5756, 1992.

[23] F. Biryan and K. Demirelli, "A methacrylate monomer bearing nitro, aryl, and hydroxyl side groups: Homopolymerization, characterization, dielectric, and thermal degradation behaviors," Journal of Applied Polymer Science, vol. 133, no. 37, Article ID APP43925, 2016.

[24] Y. Rao and C. P. Wong, "Material characterization of a highdielectric-constant polymer-ceramic composite for embedded capacitor for rf applications," Journal of Applied Polymer Science, vol. 92, no. 4, pp. 2228-2231, 2004.

[25] F. Biryan and K. Demirelli, "Copolymerization of benzyl methacrylate and a methacrylate bearing benzophenoxy and hydroxyl side groups: Monomer reactivity ratios, thermal studies and dielectric measurements," Fibers and Polymers, vol. 18, no. 9, pp. 1629-1637, 2017.

[26] M. Castro Martínez, S. Hernández López, and E. V. Santiago, "Relationship between Polymer Dielectric Constant and Percolation Threshold in Conductive Poly(styrene)-Type Polymer and Carbon Black Composites," Journal of Nanomaterials, vol. 2015, Article ID 607896, 2015.

[27] F. Biryan, K. Demirelli, G. Torğut, and G. Pıhtılı, "Synthesis, thermal degradation and dielectric properties of poly[2hydroxy,3-(1-naphthyloxy)propyl methacrylate]," Polymer Bulletin, vol. 74, no. 2, pp. 583-602, 2017.

[28] C. Zhang, C.-J. Li, G. Zhang et al., "Ionic conductivity and its temperature dependence of atmospheric plasma-sprayed yttria stabilized zirconia electrolyte," Materials Science and Engineering: B, vol. 137, no. 1-3, pp. 24-30, 2007.

[29] G. K. Prajapati and P. N. Gupta, "Comparative study of the electrical and dielectric properties of PVAPEGAl2O3MI ( $\mathrm{M}=\mathrm{Na}$, $\mathrm{K}, \mathrm{Ag}$ ) complex polymer electrolytes," Physica B: Condensed Matter, vol. 406, no. 15-16, pp. 3108-3113, 2011.

[30] R. N. Singru, W. B. Gurnule, V. A. Khati, A. B. Zade, and J. R. Dontulwar, "Eco-friendly application of p-cresol-melamineformaldehyde polymer resin as an ion-exchanger and its electrical and thermal study," Desalination, vol. 263, no. 1-3, pp. 200210, 2010.

[31] B. L. Rivas, G. V. Seguel, and C. Ancatripai, "Polymermetal complexes: Synthesis, characterization, and properties of poly(maleic acid) metal complexes with $\mathrm{Cu}(\mathrm{II}), \mathrm{Co}(\mathrm{II}), \mathrm{Ni}(\mathrm{II})$, and $\mathrm{Zn}(\mathrm{II})$, , Polymer Bulletin, vol. 44, no. 5-6, pp. 445-452, 2000.

[32] D. C. Onwudiwe, T. Arfin, and C. A. Strydom, "Fe(II) and $\mathrm{Fe}$ (III) complexes of N-ethyl-N-phenyl dithiocarbamate: Electrical conductivity studies and Thermal properties," Electrochimica Acta, vol. 127, pp. 283-289, 2014.

[33] G. Cannelli, R. Cantelli, F. Cordero, F. Trequattrini, and M. Ferretti, "Strong dependence on doping of a low-activationenergy relaxation process in $\mathrm{YBa}_{2} \mathrm{Cu}_{3} \mathrm{O}_{61} \mathrm{x}$ : Possible polaron relaxation," Physical Review B, vol. 54, no. 21, pp. 15537-15542, 1996. 

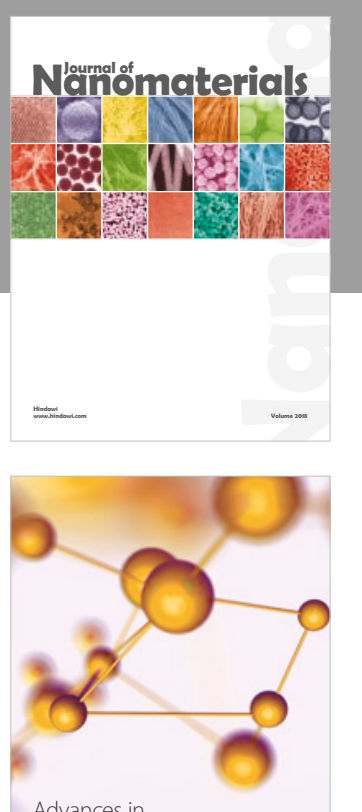

Physical Chemistry
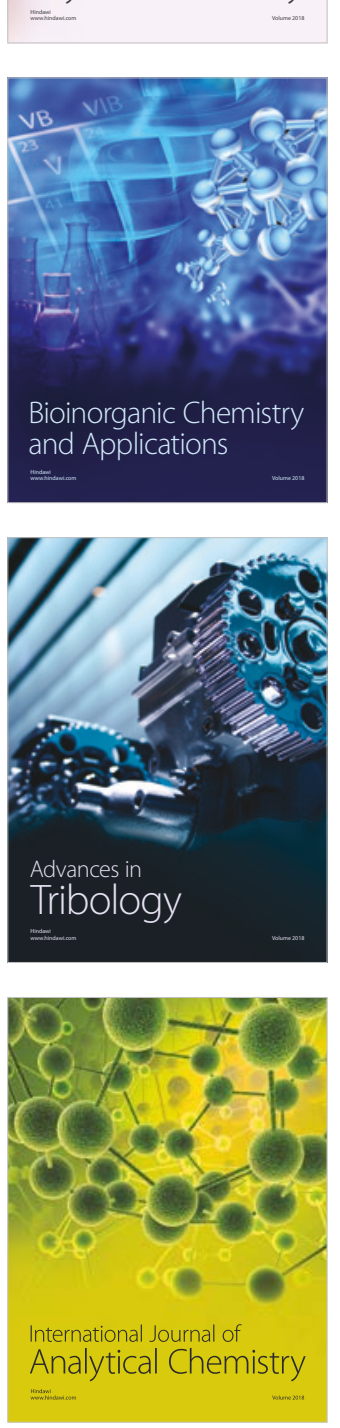

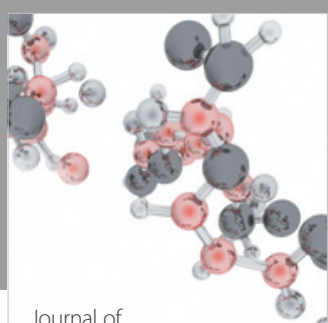

Analytical Methods

in Chemistry

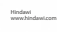

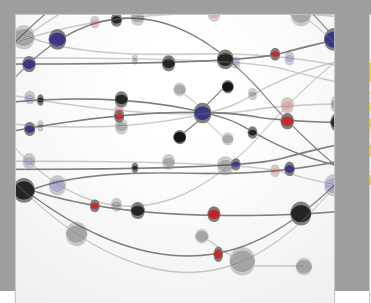

The Scientific World Journal

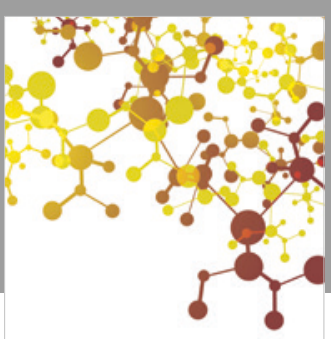

Journal of

Applied Chemistry
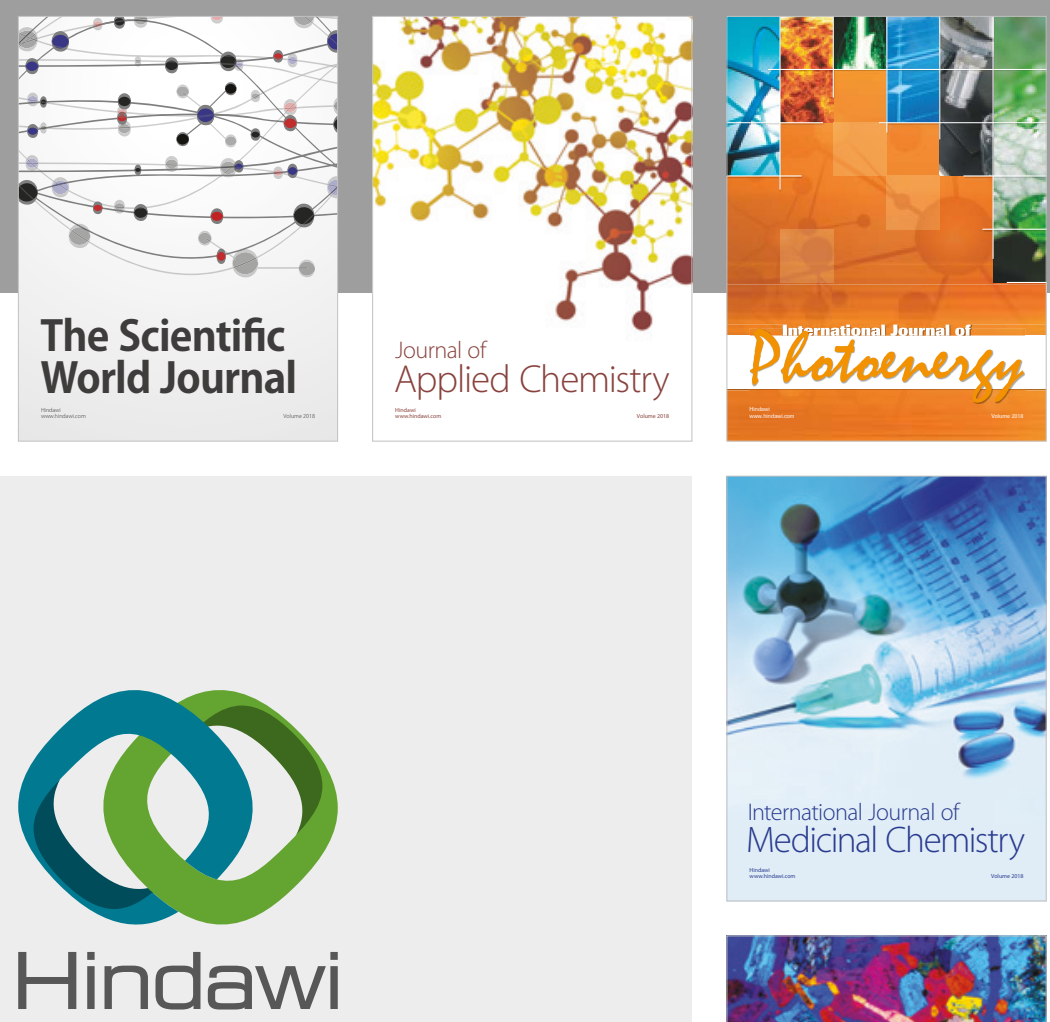

Submit your manuscripts at

www.hindawi.com
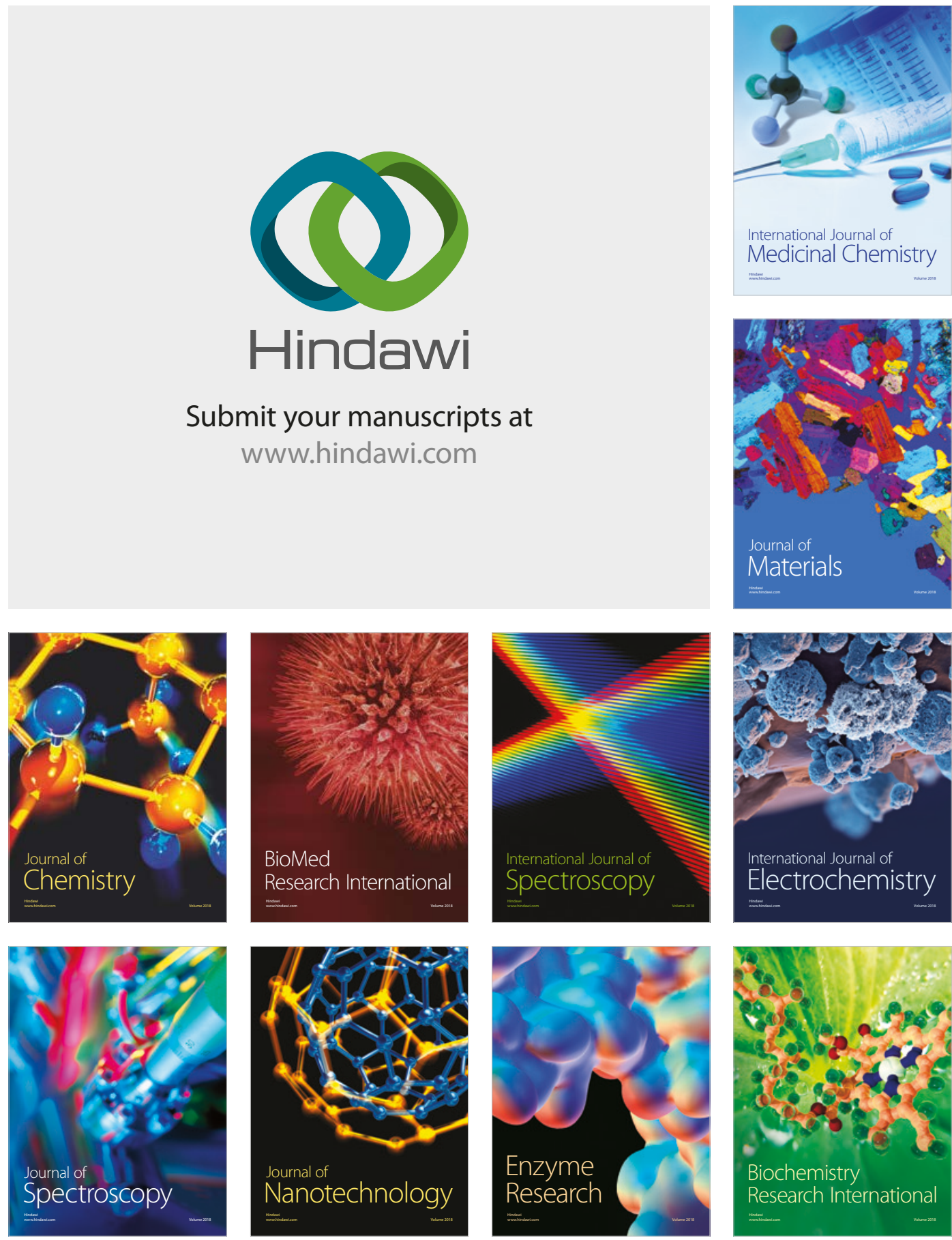
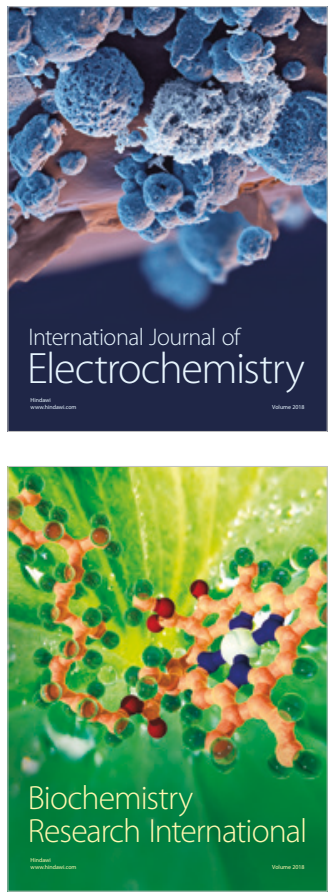